\title{
A FÍSICA NO ENEM E NO CURSO TÉCNICO DE QUÍMICA DO INSTITUTO FEDERAL DO AMAPÁ (IFAP): UMA COMPARAÇÃO CURRICULAR
}

\section{ARTIGO ORIGINAL}

CARMO, Denny Rodrigues do ${ }^{1}$, BASTOS, Argemiro Midonês², FECURY, Amanda Alves $^{3}$, DENDASCK, Carla Viana ${ }^{4}$, OLIVEIRA, Euzébio de ${ }^{5}$, DIAS, Claudio Alberto Gellis de Mattos $^{6}$

CARMO, Denny Rodrigues do. Et al. A física no ENEM e no curso técnico de química do Instituto Federal Do Amapá (IFAP): Uma comparação curricular. Revista Científica Multidisciplinar Núcleo do Conhecimento. Ano 06, Ed. 03, Vol. 03, pp. 80-88. Março de 2021. ISSN: 2448-0959, Link de acesso: https://www.nucleodoconhecimento.com.br/educacao/fisica-no-enem, DOI: 10.32749/nucleodoconhecimento.com.br/educacao/fisica-no-enem

\section{RESUMO}

O Exame Nacional do Ensino Médio (ENEM) é uma ferramenta avaliativa e seletiva para a entrada do estudante no ensino superior. Os Institutos Federais de Educação, Ciência e Tecnologia (IFs) são instituições criadas pelo governo Federal com o objetivo de formar profissionais competentes. O objetivo deste estudo é comparar o

\footnotetext{
${ }^{1}$ Estudante do Curso Técnico de Química (segundo grau) do Instituto de Ensino Básico, Técnico e Tecnológico do Amapá (IFAP).

${ }^{2}$ Físico, Doutor em Biodiversidade e Biotecnologia (UFPA), Professor e pesquisador do Curso de Licenciatura em Física do Instituto de Ensino Básico, Técnico e Tecnológico do Amapá (IFAP) e do Programa de Pós Graduação em Educação Profissional e Tecnológica (PROFEPT IFAP).

${ }^{3}$ Biomédica, Doutora em Doenças Topicais, Professora e pesquisadora do Curso de Medicina do Campus Macapá, Universidade Federal do Amapá (UNIFAP).

${ }^{4}$ Teóloga, Doutora em Psicanálise, pesquisadora do Centro de Pesquisa e Estudos Avançados- CEPA.

${ }^{5}$ Biólogo, Doutor em Doenças Topicais, Professor e pesquisador do Curso de Educação Física da, Universidade Federal do Pará (UFPA).

${ }^{6}$ Biólogo, Doutor em Teoria e Pesquisa do Comportamento, Professor e pesquisador do Curso de Licenciatura em Química do Instituto de Ensino Básico, Técnico e Tecnológico do Amapá (IFAP) e do Programa de Pós Graduação em Educação Profissional e Tecnológica (PROFEPT IFAP).
}

RC: 77706

Disponível em: https://www.nucleodoconhecimento.com.br/educacao/fisica-no-enem 
conteúdo das questões de Física do Exame Nacional do Ensino Médio (ENEM) entre os anos de 2014 a 2018 com o conteúdo curricular do curso técnico de química do Instituto Federal do Amapá (IFAP). O ensino de física no curso técnico de Química do IFAP não apresenta uma divisão que prioriza os assuntos mais presentes no ENEM. O ENEM costuma contextualizar suas questões. Isso poderia ser uma prática comum no ensino médio da física, pois ajudaria na sua melhor compreensão. Além disso se faz necessário a não fragmentação do conteúdo durante o ensino, nem como sua composição com outras disciplinas. O curso técnico do IFAP não seria o local apropriado de estudo para quem deseja apenas terminar o ensino médio. $O$ conteúdo vai além do exigido, porém com recortes voltados para a parte técnica, incluindo praticas laboratoriais e disciplinas estritamente técnicas. A ausência de interdisciplinaridade e contextualização dificulta a absorção do conteúdo, formando discentes com dificuldade de pensar a física.

Palavras-chave: ENEM, EPT, Ensino, Física, IFAP.

\section{INTRODUÇÃO}

Criado pelo governo Federal do Brasil, em 1998, o Exame Nacional do Ensino Médio (ENEM) tinha o objetivo de avaliar os estudantes que completaram o ensino médio. Com o passar do tempo, o ENEM obteve mais relevância ao ser utilizado não só como ferramenta avaliativa, mas também como uma ferramenta seletiva para a entrada do estudante no ensino superior (Silveira et al., 2015).

$\mathrm{Na}$ prova do ENEM, a disciplina de física é abordada junto com as disciplinas de biologia e química na área de conhecimento Ciência da Natureza. Mesmo não havendo uma separação formal, é possível perceber que as questões de Ciências da Natureza podem ser organizadas entre as três disciplinas analisando-se os conteúdos abordados. (Silveira et al., 2015).

Os Institutos Federais de Educação, Ciência e Tecnologia são instituições criadas pelo governo Federal com o objetivo de formar profissionais competentes. Estes

$\mathrm{RC}: 77706$

Disponível em: https://www.nucleodoconhecimento.com.br/educacao/fisica-no-enem 
podem apresentar diversos cursos como licenciaturas, mestrados ou doutorados, mas a principal modalidade é o ensino técnico, principalmente o ensino técnico integrado com o ensino médio (Pacheco, 2010).

No Brasil, todos os estados apresentam pelo menos um Instituto Federal, alguns apresentam até mais do que um, totalizando 38 unidades. Um Instituto Federal pode ser dividido em campi, no total atual de 644 em funcionamento. (Brasil, 2018).

O Instituto Federal de Educação, Ciência e Tecnologia do Estado do Amapá (IFAP) foi criado em 28 de dezembro de 2008 com a Lei no 11.892 (Marques et al., 2020) e tem o objetivo de contribuir para o desenvolvimento do estado (Castro et al., 2020). O IFAP oferta cursos que vão do superior ao ensino médio, e com isso, ele consegue atingir um amplo público de diferentes níveis, ele também é constituído por vários campi, dos quais podemos citar o campus Macapá, localizado na capital (Brasil, 2019; Penha et al., 2020).

O campus Macapá oferta o curso Técnico em Química de nível médio na forma integrada. Nesse curso temos os componentes curriculares da Base Nacional Comum referentes as áreas de linguagens, matemática, ciências humanas e ciências da natureza. Dentro da área de ciências da natureza, temos o componente curricular de física que é abordado durante os três anos do curso. Cada ano apresenta carga horária de 80 horas anuais e os conteúdos ensinados são organizados em quatro unidades, totalizando 12 unidades ao longo dos três anos. (Brasil, 2016).

No Instituto Federal do Amapá (IFAP) os assuntos da ementa do componente "Física" do primeiro ano do curso técnico integrado integral são: Introdução à Física e Cinemática; Dinâmica; Trabalho e Energia (que também inclui Quantidade de movimento e Impulso); Gravitação e Estática dos Fluidos. No segundo ano a matriz curricular comtempla: Calor e Temperatura; Termodinâmica; Óptica Geométrica; Oscilações e Ondas (que também inclui Movimento Harmônico Simples). No terceiro 
e último ano os conteúdos são: Eletrostática; Eletrodinâmica; Magnetismo; e Eletromagnetismo (Brasil, 2016).

Dentro da matriz curricular do Enem, existem as competências e os objetos de conhecimento relacionados a essas competências. Os objetos de conhecimento relacionados a física são cobrados dentro de 7 tópicos: Conhecimentos básicos e fundamentais (que inclui assuntos de Análise Dimensional e Sistemas de Unidades); o movimento, o equilíbrio e a descoberta de leis físicas (que inclui, Cinemática, Dinâmica, Hidrostática, Estática, Impulso e Quantidade de Movimento); energia, trabalho e potência (que inclui assuntos relacionados a Trabalho e Energia); a mecânica e o funcionamento do universo (que inclui assuntos relacionados a Gravitação); os fenômenos elétricos e magnéticos (com assuntos referentes a Eletricidade e Magnetismo); oscilações, ondas, óptica e radiação (que inclui assuntos de Óptica a Ondulatória); e o calor e os fenômenos térmicos (que inclui assuntos referentes a Termologia) (Brasil, 2015).

\section{OBJETIVOS}

Comparar o conteúdo das questões de Física do Exame Nacional do Ensino Médio (ENEM) entre os anos de 2014 a 2018 com o conteúdo curricular do curso técnico de química do Instituto Federal do Amapá (IFAP).

\section{MATERIAL E MÉTODOS}

A pesquisa foi realizada utilizando questões do Exame Nacional do Ensino Médio (ENEM) retiradas do programa (software) Super professor, adquirido da empresa Interbits Informática (https://www.sprweb.com.br/mod_superpro/index.php). No programa foi selecionada a disciplina física e os anos de 2014 a 2018. Utilizou-se classificação das questões de acordo com o programa (após análise e retirada de questões sobrepostas). Posteriormente fez-se uma comparação entre estas e o conteúdo programático do componente física do curso técnico do Instituto Federal do Amapá (IFAP). A pesquisa bibliográfica foi realizada em artigos científicos, em

RC: 77706

Disponível em: https://www.nucleodoconhecimento.com.br/educacao/fisica-no-enem 
computadores do Instituto no Instituto Federal de Educação, Ciência e Tecnologia do Amapá, Campus Macapá, situado à Rodovia BR 210 KM 3, s/n - Bairro Brasil Novo. CEP: 68.909-398, Macapá, Amapá, Brasil. Os dados foram compilados no aplicativo Excel, componente do pacote Office da Microsoft Corporation.

\section{RESULTADOS}

A classificação do conteúdo sobreposto das questões de física do ENEM entre 2014 e 2018, por quantidade e porcentagem de questões aparece na tabela 1. Três (3) assuntos não apresentam nenhuma questão (Análise dimensional/sistema de unidades, gravitação e física moderna). A maior parte dos assuntos apresentam uma (1) ou duas (2) questões. Eletricidade + Magnetismo e Cinemática apresentam 4 questões cada um. Seis (6) das questões são tanto para o assunto de Trabalho e Energia quanto para o assunto de Óptica. $\mathrm{O}$ assunto Ondulatória engloba um total de 17 questões.

RC: 77706

Disponível em: https://www.nucleodoconhecimento.com.br/educacao/fisica-no-enem 
Tabela 1 Classificação do conteúdo sobreposto das questões de física do ENEM entre 2014 e 2018, por quantidade e porcentagem de questões.

\begin{tabular}{l|c|c}
\hline \multicolumn{3}{c}{ Classificação do autor após análise de conteúdo sobreposto } \\
\hline \multicolumn{1}{c|}{ Cósica } & Quantidade & Porcentagem \\
\hline Análise Dimensional / Sistemas de Unidades & 0 & $0 \%$ \\
\hline Gravitação & 0 & $0 \%$ \\
\hline Moderna & 0 & $0 \%$ \\
\hline Cinemática + Impulso e Quantidade de Movimento & 1 & $2 \%$ \\
\hline Dinâmica + Impulso e Quantidade de Movimento & 1 & $2 \%$ \\
\hline Hidrodinâmica & 1 & $2 \%$ \\
\hline Hidrostática & 1 & $2 \%$ \\
\hline Trabalho e Energia + Movimento Harmônico & 1 & $2 \%$ \\
\hline Temática + Trabalho e energia & 1 & $2 \%$ \\
\hline Tematica & 1 & $2 \%$ \\
\hline Cinemática + Dinâmica & 2 & $3 \%$ \\
\hline Dinâmica & 2 & $3 \%$ \\
\hline Estática & 2 & $3 \%$ \\
\hline Impulso e Quantidade de Movimento & 2 & $3 \%$ \\
\hline Trabalho e Energia + termologia & 2 & $3 \%$ \\
\hline Eletricidade + Magnetismo & 4 & $7 \%$ \\
\hline Cinemática & 4 & $7 \%$ \\
\hline Trabalho e Energia & 6 & $10 \%$ \\
\hline Óptica & 6 & $10 \%$ \\
\hline Termologia & 7 & $11 \%$ \\
\hline Ondulatória & 17 & $28 \%$ \\
\hline & 61 & $\mathbf{1 0 0} \%$ \\
\hline
\end{tabular}

A tabela 2 mostra os assuntos da ementa de física do curso técnico em química do IFAP, mostrando o número da unidade (por bimestre) e o ano que são abordados. As unidades de I a IV tem que ser ministradas em oitenta (80) horas aula. No primeiro ano utiliza-se normalmente 12 horas para ministrar a unidade I, 28 horas para ministrar a unidade II, 20 horas para a unidade III, e 20 horas para a unidade IV. No segundo ano a unidade I é lecionada usualmente em 20 horas, assim como cada uma das unidades posteriores (II, III e IV). No terceiro ano a unidade I é

RC: 77706

Disponível em: https://www.nucleodoconhecimento.com.br/educacao/fisica-no-enem 
integralizada em 16 horas, a unidade II em 36 horas, a unidade III em 14 horas, e a unidade IV em também 14 horas.

Tabela 2. Assuntos da ementa de física do curso técnico em química do IFAP, por ano e unidade.

\begin{tabular}{|c|c|c|c|c|c|c|}
\hline \multirow[b]{2}{*}{ Unidade } & \multicolumn{6}{|c|}{ Ano } \\
\hline & $1^{\circ}$ Ano & $\begin{array}{c}\mathrm{n}^{\circ} \text { de horas } \\
\text { aulas }\end{array}$ & $2^{\circ}$ Ano & $\begin{array}{c}\mathrm{n}^{\circ} \text { de horas } \\
\text { aulas }\end{array}$ & $3^{\circ}$ Ano & $\begin{array}{c}\mathrm{n}^{\circ} \text { de horas } \\
\text { aulas }\end{array}$ \\
\hline I & \begin{tabular}{|c|} 
Introdução à \\
Fisica e \\
Cinemática \\
\end{tabular} & 12 & $\begin{array}{c}\text { Calore } \\
\text { Temperatura }\end{array}$ & 20 & Eletrostática & 16 \\
\hline II & $\begin{array}{c}\text { Dinâmica } \\
\text { (evidenciando o } \\
\text { conceito de força } \\
\text { e aplicações) } \\
\end{array}$ & 28 & Termodinâmica & 20 & Eletrodinâmica & 36 \\
\hline III & $\begin{array}{c}\begin{array}{c}\text { Trabalho e } \\
\text { Energia }\end{array} \\
\end{array}$ & 20 & $\begin{array}{c}\text { Óptica } \\
\text { Geométrica }\end{array}$ & 20 & Magnetismo & 14 \\
\hline IV & $\begin{array}{c}\text { Gravitação e } \\
\text { Estática dos } \\
\text { Fluidos }\end{array}$ & 20 & $\begin{array}{l}\text { Oscilações e } \\
\text { Ondas }\end{array}$ & 20 & Eletromgnetismo & 14 \\
\hline $\begin{array}{l}\text { no aulas da } \\
\text { matriz anual }\end{array}$ & & 80 & & 80 & & 80 \\
\hline
\end{tabular}

A classificação simplificada do conteúdo das questões de física do ENEM entre 2014 e 2018, por quantidade e porcentagem de questões está demonstrada na tabela 3. A assunto Temática aparece em $2 \%$ das questões, seguido do assunto Eletricidade+Magnestimo (7\%), òptica (10\%), Termologia (11\%); Ondulatória (28\%), e Mecânica (43\%).

RC: 77706

Disponível em: https://www.nucleodoconhecimento.com.br/educacao/fisica-no-enem 
Tabela 3. Classificação simplificada do conteúdo das questões de física do ENEM entre 2014 e 2018, por quantidade e porcentagem de questões.

\begin{tabular}{l|c|c|}
\hline Assunto & Quantidade & Porcentagem \\
\hline Tematica & 1 & $2 \%$ \\
\hline Eletricidade + Magnetismo & 4 & $7 \%$ \\
\hline Óptica & 6 & $10 \%$ \\
\hline Termologia & 7 & $11 \%$ \\
\hline Ondulatória & 17 & $28 \%$ \\
\hline Mecânica & 26 & $43 \%$ \\
\hline Total & $\mathbf{6 1}$ & $\mathbf{1 0 0 \%}$ \\
\hline
\end{tabular}

A classificação simplificada do conteúdo das questões de física do ENEM entre 2014 e 2018, dividas pelo ano em que são ensinados no curso técnico em química do IFAP estão na tabela 4. A porcentagem sendo mostrada se refere a parcela de questões do ENEM dentro de cada assunto.

Tabela 4. Classificação simplificada do conteúdo das questões de física do ENEM entre 2014 e 2018, dividas pelo ano em que são ensinados no curso técnico em química do IFAP

\begin{tabular}{|c|c|c|c|c|}
\hline & \multicolumn{4}{|c|}{ Curso técnico em química do IFAP } \\
\hline & $1^{\circ}$ & $2^{\circ}$ & $3^{\mathrm{a}}$ & Todos \\
\hline \multirow{3}{*}{$\begin{array}{c}\text { Assuntos com } \\
\text { as porcentagem } \\
\text { de questões }\end{array}$} & \multirow{3}{*}{ Mecânica (43\%) } & Óptica (10\%) & \multirow{3}{*}{$\begin{array}{c}\text { Eletricidade }+ \\
\text { Magnestismo (7\%) }\end{array}$} & \multirow{3}{*}{ Tematica $(2 \%)$} \\
\hline & & Termologia (11\%) & & \\
\hline & & Ondulatória (28\%) & & \\
\hline $\begin{array}{l}\text { Porcentagem } \\
\text { Total }\end{array}$ & $43 \%$ & $49 \%$ & $7 \%$ & $100 \%$ \\
\hline
\end{tabular}

A figura 1 mostra a quantidade de questões de física no ENEM entre 2014 e 2018 segundo o grau de dificuldade. As questões classificadas pelo programa Super

RC: 77706

Disponível em: https://www.nucleodoconhecimento.com.br/educacao/fisica-no-enem 
professor como de baixa dificuldade diminuíram em quantidade de 2014 a 2016, voltando a aumentar de 2016 a 2018. As de média dificuldade aumentaram de 2014 a 2016, e diminuíram de 2016 a 2018. As consideradas de alta dificuldade aparecem somente em 2015.

Figura 1 Quantidade de questões de física no ENEM entre 2014 e 2018 segundo o grau de dificuldade

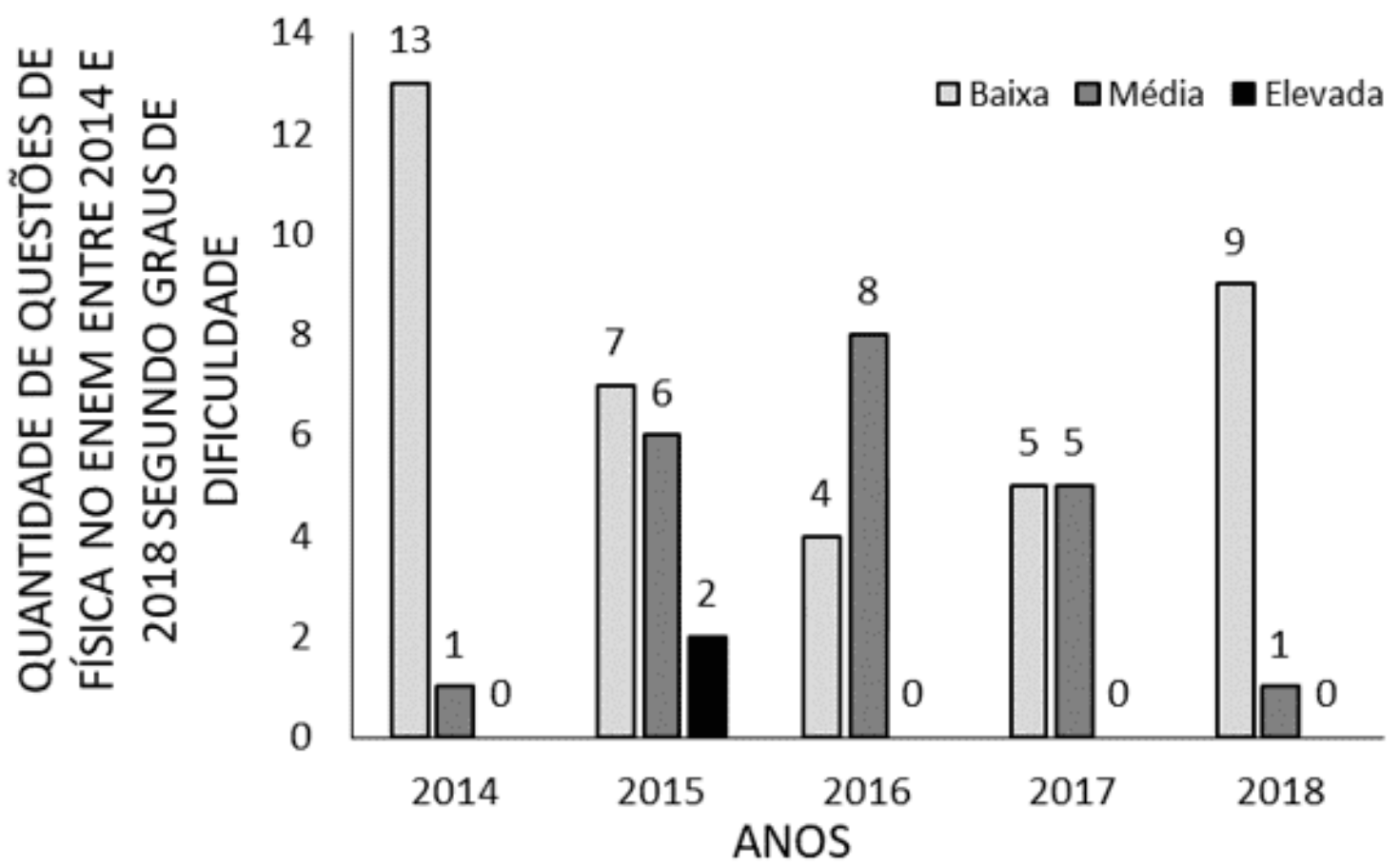

\section{DISCUSSÃO}

O Exame Nacional de Ensino Médio tem por parâmetro contextualizar as questões da prova de física ligando-as ao cotidiano das pessoas (Silveira et al., 2014). Nesse sentido, a diferença apresentada entre os assuntos da avaliação de física no período estudado (tabela 1) pode ter ocorrido como consequência desta contextualização. Em um estudo sobre a presença da física no cotidiano de estudantes que trabalham detectou-se questionamentos sobre uso de energias diversas (elétrica, química), em situações como usinas de produção de álcool e locais de instalação de

RC: 77706

Disponível em: https://www.nucleodoconhecimento.com.br/educacao/fisica-no-enem 
equipamentos sonoros em automóveis (Toti e Pierson, 2010). A óptica também aparece rotineiramente na vida das pessoas. O estudo da luz pode auxiliar um engenheiro a saber quanta sombra seu prédio projetado irá causar na vizinhança; ou como uma xícara ou um objeto metálico rele-te uma imagem ; ou até porque o céu apresenta a cor azul, quando o dia está ensolarado (Ribeiro e Verdeaux, 2012).

No curso técnico, como parte de eletromagnetismo, há a introdução à relatividade especial, que é um assunto de física moderna (Brasil, 2016). A física moderna no ensino médio ainda não é um conteúdo consolidado e falta consenso sobre seu ensino. Provavelmente por isso a ausência deste tópico no ENEM (Silva et al., 2013).

Costumeiramente, os currículos dividem o ano letivo do ensino médio em quatro bimestres. Cada bimestre corresponde a uma unidade, com 20 horas cada. Em um ano com 80 horas, a divisão seria então equitativa. Porém, alguns assuntos são mais demorados que outros para serem lecionados (tabela 2). A diferença entre o tempo planejado e o tempo real para cada unidade se deve provavelmente a programação fragmentada do conteúdo. Desta maneira, o aprendizado se torna não encadeado, e os conteúdos apresentados, fragmentados, tem fatores de dificuldade diferentes, exigindo menos ou mais horas para sua conclusão (Gaspar, 1997). Além disso o tempo de aula em uma sala tradicional é também gasto com outras tarefas (chamada, anotações) e não com o ensino da disciplina em si (Pires e Veit, 2006).

Na matriz de referência do Enem, a maioria dos objetos de estudo são relacionados a mecânica. Nessa mesma matriz, os assuntos de ondulatória, óptica , eletromagnetismo e termodinâmica possuem uma quantidade parecida de objetos. Mas, a presença desses assuntos nas questões não é parecida. Apenas mecânica é muito presente tanto nessa matriz quanto nas questões (tabela 3). A matriz de referencia engloba, no tópico mecânica, muitos conceitos diferenciados, o que não ocorre com outros assuntos como, por exemplo, ondulatória. Talvez essa divisão praticada pelo ENEM e diferente da divisão do ensino médio técnico, ocasione a diferença percentual observada (Brasil, 2015).

RC: 77706

Disponível em: https://www.nucleodoconhecimento.com.br/educacao/fisica-no-enem 
Alguns conteúdos ministrados no componente física dentro do curso técnico de química do IFAP tem, por exemplo, carga de 80 horas (eletricidade + magnetismo) e corresponde a $7 \%$ do conteúdo cobrado no ENEM. Outros, como termologia, são ministrados no ensino técnico em 40 horas e correspondem a $11 \%$ do exame nacional. Outros ainda, como ondulatória, representam $28 \%$ da avaliação do ENEM e são lecionados em 20 horas. Essa disparidade provavelmente ocorre porque o papel fundamental do IFAP, no curso citado, é formar técnicos em química (Brasil, 2019). O que não significa que os estudantes que concluem o ensino médio técnico não prestem o ENEM para ingressar no nível superior.

O ensino de física ainda apresenta dificuldades quanto a absorção de conhecimentos por parte dos discentes, o que faz com que a maioria dos alunos não apresente desempenho satisfatório nesta disciplina (Sbf, 2011; Barroso et al., 2018).

A prova do ENEM deveria ser condizente com o que o aluno aprendeu no ensino médio (normal ou técnico). Foi possível ver que a dificuldade do ENEM mudou durante os anos (figura 1). A tentativa de aumentar a dificuldade das questões do exame nacional (2014 a 2016) foi revertida nos dois anos subsequentes. Provavelmente como o ensino de física no nível médio apresenta ainda um desempenho baixo de absorção de conhecimentos, talvez isto tenha influenciado na decisão de abaixar o nível de dificuldade deste componente nos exames de 2017 e 2018 (Barroso et al., 2018).

\section{CONCLUSÃO}

O ensino de física no curso técnico de Química do IFAP não apresenta uma divisão que prioriza os assuntos mais presentes no ENEM.

O ENEM costuma contextualizar suas questões. Isso poderia ser uma prática comum no ensino médio da física, pois ajudaria na sua melhor compreensão. Além disso se faz necessário a não fragmentação do conteúdo durante o ensino, nem como sua composição com outras disciplinas.

RC: 77706

Disponível em: https://www.nucleodoconhecimento.com.br/educacao/fisica-no-enem 
O curso técnico do IFAP não seria o local apropriado de estudo para quem deseja apenas terminar o ensino médio. O conteúdo vai além do exigido, porém com recortes voltados para a parte técnica, incluindo praticas laboratoriais e disciplinas estritamente técnicas.

A ausência de interdisciplinaridade e contextualização dificulta a absorção do conteúdo, formando discentes com dificuldade de pensar a física.

\section{REFERÊNCIAS}

BARROSO, M. F.; RUBINI, G.; SILVA, T. Dificuldades na aprendizagem de Física sob a ótica dos resultados do Enem. Rev. Bras. Ensino Fís., v. 40, n. 4, p. e4402, 2018.

BRASIL. Matriz de Referência Enem. Brasilia DF, 2015. Disponível em: < http://download.inep.gov.br/download/enem/matriz_referencia.pdf >. Acesso em: 25 mar 2020.

. Curso Técnico de Nível Médio em Química na Forma Integrada Regime Integral: Plano de Curso. Macapá AP, 2016. Disponível em: < https://portal.ifap.edu.br/index.php/publicacoes/item/1100-resolucao-n-20-2018consup >. Acesso em: 27 abril 2019.

. Expansão da Rede Federal. Rede Federal de Educação Profissional, Científica e Tecnológica. 2018. Disponível em: < http://redefederal.mec.gov.br/expansao-da-rede-federal >. Acesso em: 27 abril 2019. . Curso Técnico em Química - Integrado - Campus Macapá. Macapá AP, 2019. Disponível em: < http://www.ifap.edu.br/index.php/component/content/article?id=398 >. Acesso em: 27 abril 2019.

RC: 77706

Disponível em: https://www.nucleodoconhecimento.com.br/educacao/fisica-no-enem 
CASTRO, G. N. V. et al. Análise de Eficiência Acadêmica dos cursos subsequentes, nas modalidades à distância e presencial, ofertados pelo Instituto Federal do Amapá (2018). Research, Society and Development, v. 9, n. 8, p. e208985262, 2020. https://rsdjournal.org/index.php/rsd/article/view/5262

GASPAR, A. Cinqüenta anos de ensino de Física: Muitos equívocos, alguns acertos e a necessidade do resgate do papel do professor $\underline{X V \text { Encontro de }}$ Físicos do norte e Nordeste Natal RN 1997.

MARQUES, J. D. C. et al. Nível Médio Técnico e Cursos de Graduação: comparativo de vagas e ingressantes no Instituto Federal do Amapá, Brasil (20172018). Research, Society and Development, v. 9, n. 8, p. e228985375, 2020 https://rsdjournal.org/index.php/rsd/article/view/5375

PACHECO, E. M. Os Institutos Federais: Uma Revolução na Educação Profissional e Tecnológica. Natal RN: IFRN, 2010. 28p.

PENHA, A. C. F. M. et al. Matrículas da Educação Especial na Educação Profissional Técnica de Nível Médio no Estado do Amapá (2015-2018). Research, Society and Development, v. 9, n. 7, p. e881974867, 2020. https://rsdjournal.org/index.php/rsd/article/view/4867

PIRES, M. A.; VEIT, E. A. Tecnologias de Informação e Comunicação para ampliar e motivar o aprendizado de Fisica no Ensino Medio. Revista Brasileira de Ensino de Fisica, v. 28, n. 2, p. 241 - 248, 2006.

RIBEIRO, J. L. P.; VERDEAUX, M. D. F. D. S. Atividades experimentais no ensino de óptica: uma revisão. Revista Brasileira de Ensino de Fısica, v. 34, n. 4, p. 1 10, 2012.

SBF. Carta aberta ao Inep quanto à adoção do Exame Nacional do Ensino Médio como critério de ingresso nas Universidades. São Paulo SP, 2011. Disponível em:

RC: 77706

Disponível em: https://www.nucleodoconhecimento.com.br/educacao/fisica-no-enem 
< http://www.sbfisica.org.br/v1/arquivos_diversos/noticias/maio2014/carta-aoINEP.pdf >. Acesso em: 05 fev 2021.

SILVA, J. R. N. D.; ARENGHI, L. E. B.; LINO, A. Porque inserir física moderna e contemporânea no ensino médio? Uma revisão das justificativas dos trabalhos acadêmicos. R. B. E. C. T., v. 6, n. 1, p. 1-15, 2013.

SILVEIRA, F. L.; BARBOSA, M. C. B.; SILVA, R. Exame Nacional do Ensino Médio (ENEM): Uma análise crítica Rev. Bras. Ensino Fís., v. 37, n. 1, p. 1101, 2015.

SILVEIRA, F. L.; STILCK, J.; BARBOSA, M. Comunicações: Manifesto sobre a qualidade das questões de Física na Prova de Ciências da natureza no Exame Nacional de Ensino Médio. Caderno Brasileiro de Ensino de Física, v. 31, n. 2, p. 473-479, 2014.

TOTI, F. A.; PIERSON, A. H. C. Elementos para uma aproximação entre a física no ensino médio e o cotidiano de trabalho de estudantes trabalhadores. Investigações em Ensino de Ciência, v. 15, n. 3, p. 527-552, 2010

Enviado: Março, 2021

Aprovado: Março, 2021

RC: 77706

Disponível em: https://www.nucleodoconhecimento.com.br/educacao/fisica-no-enem 